\title{
ANALYSIS OF THE CHEMICAL REACTIVITY OF INDAZIFLAM HERBICIDE AND ITS METABOLITES THROUGH GLOBAL AND LOCAL REACTIVITY DESCRIPTORS
}

\author{
Luis Humberto Mendoza-Huizar ${ }^{\mathrm{a}, *,(\mathbb{D})}$, Clara Hilda Rios-Reyes ${ }^{\mathrm{b}}$, Giaan Arturo Álvarez-Romero and María Elena Páez- \\ Hernández ${ }^{\mathrm{a}}$ \\ aÁrea Académica de Química, Universidad Autónoma del Estado de Hidalgo, Carretera Pachuca-Tulancingo Km. 4.5, Mineral de \\ la Reforma, Hidalgo, Mexico \\ b2Artes, San Felipe 215, Providence, Mineral de la Reforma, Hidalgo, Mexico
}

Recebido em 19/05/2019; aceito em 11/06/2019; publicado na web em 01/07/2019

\begin{abstract}
In the present work, the chemical reactivity of indaziflam $\mathrm{N}$-[(1R,2S)-2,3-dihydro-2,6-dimethyl-1H-inden-1-yl]-6-[(1R)-1-16 fluoroethyl]-1,3,5-triazine-2,4-diamine so called indaziflam (IND) and its metabolites: triazine indanone (ITI), indaziflam carboxylic acid (ICA) and fluoroethyldiaminotriazine (FDAT) was analyzed. The calculations were performed at the X/6-311++G(2d,2p) (where $\mathrm{X}=\mathrm{B} 3 \mathrm{LYP}, \mathrm{M} 06, \mathrm{M} 06 \mathrm{~L}$ and wB97XD) level of theory, in the aqueous phase. The results indicate that ITI is the more reactive followed by ICA, IND and FDAT. The distribution of the active sites was determined evaluating the Fukui function employing the frozen core and finite difference approximations. For electrophilic attacks, IND shows the more reactive zone on the benzene ring, ITI and ICA on the nitrogen atom in the central section and FDAT on its nitrogen atoms. The more nucleophilic sites for IND are observed on the carbon atoms of triazine, on the carbonyl group for ITI, on the carboxylic group for ICA, and on the nitrogen atoms of triazine for FDAT. For free radical attacks case, the more reactive sites for IND are on the benzene and triazine rings, on the carbonyl group, nitrogen of the central section, and nitrogen atoms of triazine, for ITI, carboxylic group for ICA, and on the nitrogen atoms of triazine ring for FDAT.
\end{abstract}

Keywords: indaziflam; Fukui function; dual descriptor, DFT.

\section{INTRODUCTION}

Indaziflam, (N-[(1R,2S)-2,3-dihydro-2,6-dimethyl-1H-inden1-yl]-6-[(1R)-1-16 fluoroethyl]-1,3,5-triazine-2,4-diamine) is an alkylazine herbicide, see Figure 1a, which acts inhibiting the biosynthesis of the cell wall, and paralyzing the development of the plant. ${ }^{1-4}$ Indaziflam (IND) is considered as the most potent inhibitor of the cell wall ever discovered and is widely used in preemergence control of monocot and dicot weeds in commercial crop production, turf, commercial non-crop areas, field grown ornamentals, commercial nurseries, landscape plantings, and forestry sites. ${ }^{5}$

IND is lipophilic and has low water solubility $\left(2.8 \mathrm{mg} \cdot \mathrm{L}^{-1}\right)$, which could explain its increased residual soil activity compared to other herbicides. ${ }^{6,7}$ Moreover, its positive correlation between sorption and organic matter contents indicates that its long persistence of residual activity in soil requires that it be used with caution, because of its carryover potential. ${ }^{3}$ IND dissipates in the environment primarily through degradation and leaching. The main transformation chemicals from the environmental degradation of indaziflam are: indaziflam triazine-indanone (ITI), indaziflam-carboxylic acid (ICA), fluoroethyldiaminotriazine (FDAT), indaziflam-hydroxyethyl, indaziflam-olefin, and fluoroethyltriazinanedione. Also, it has been reported in the literature that IND, ITI and ICA are cleaved at the N bond to form FDAT (from the triazine portion) and a set of unidentified minor compounds (from the indazyl portion) ${ }^{8}$ On the other hand, indaziflam metabolites, see Figure 1b-d, are more mobile than the parent material, and they have been found in some soils samples at a considerable depth. ${ }^{8}$ Moreover, these metabolites being more polar than the parent compound showed lower sorption; ${ }^{9}$ therefore, they have the potential to persist and leach to groundwater. ${ }^{10}$ Here, it is important to remind that the leaching potential of a herbicide is directly connected to the contamination of water resources in the underground. ${ }^{11}$ In this sense, IND has been detected in soil samples collected at each depth, suggesting movement with irrigation water. ${ }^{12}$ Thus, as other pre-emergence herbicides applied to soil, it is necessary to understand the fate and chemical behavior of this herbicide and its metabolites to understand the potential risk of contamination of water resources. ${ }^{13} \mathrm{Up}$ to the best our knowledge, information published concerning the water contamination caused by IND is scarce, and none concerning any of its metabolites. Solely on the basis of sorption, IND would be assigned a low to moderate mobility. ${ }^{14,15}$ However, due to its environmental persistence it would become a potential emergent water contaminant. ${ }^{16}$ Therefore, in the present work we carried out a computational quantum chemical study of IND and its metabolites in order to evaluate their global and local reactivity descriptors in the aqueous phase, we consider that this kind of study will contribute to get a better understanding of the chemical behavior of this herbicide and its metabolites.

\section{THEORY}

\section{Global reactivity parameters}

From the Density functional theory have been defined global reactivity parameters such as the electronic chemical potential $(\mu)$, the electronegativity $(\chi)$, hardness $(\eta)$ and the electrophilicity index $(\omega)$, which are used to understand the general chemical behavior of a molecule. ${ }^{17,18}$ They are evaluated within the framework of the DFT through equations (1)-(4), respectively. ${ }^{19-22}$

$$
\mu=\left(\frac{\partial E}{\partial N}\right)_{v(r)}=-\frac{1}{2}(I+A)=\frac{1}{2}\left(\varepsilon_{L}+\varepsilon_{H}\right)
$$

$$
\chi=-\mu
$$


a)<smiles>Cc1ccc2c(c1)[C@H](Nc1nc(N)nc(C(C)F)n1)[C@H](C)C2</smiles>

c)<smiles>CC(F)c1nc(N)nc(N[C@H]2c3cc(C(=O)O)ccc3C[C@@H]2C)n1</smiles>

b)<smiles>Cc1ccc2c(c1)[C@H](Nc1nc(N)nc(C(C)F)n1)[C@H](C)C2=O</smiles>

d)<smiles>CC(F)c1nc(N)nc(N)n1</smiles>

Figure 1. Chemical structures of indaziflam and its three metabolites a) IND, b) ITI, c) ICA and d) FDAT

$$
\begin{gathered}
\eta=\left(\frac{\partial \mu}{\partial N}\right)_{v(r)}=\left(\frac{\partial^{2} E}{\partial N^{2}}\right)_{v(r)}=(I-A)=\left(\varepsilon_{L}-\varepsilon_{H}\right) \\
\omega=\frac{\mu^{2}}{2 \eta}
\end{gathered}
$$

In these equations, the variables $E, N$ and $v(\mathrm{r})$ are the energy, number of electrons and the external potential exerted by the nuclei, respectively. $I$ is the ionization potential while $A$ corresponds to the electronic affinity. In this sense, some reports suggest that the Koopmans' theorem may become valid for calculations of the global reactivity parameters at the DFT level. ${ }^{23-25}$ Under this approximation, $A$ is related to the minus the Lowest Unoccupied Molecular Orbital (LUMO) energy $\left(\varepsilon_{\mathrm{L}}\right)$, while $I$ is associated with the minus Highest Occupied Molecular Orbital (HOMO) energy $\left(\varepsilon_{\mathrm{H}}\right){ }^{23-25}$ The electronic chemical potential is associated to the escaping tendency of an electron and is minus the Mulliken electronegativity of molecules, ${ }^{26}$ the value of $\eta$ is related to the stability of the molecular system..$^{19,27}$ while $\omega$ measures the susceptibility of chemical species to accept electrons. ${ }^{28}$ Thus, low values of $\omega$ suggest a good nucleophile while higher values indicate the presence of a good electrophile. Also, it is possible to define the electrodonating $\left(\omega^{-}\right)$and electroaccepting $\left(\omega^{+}\right)$powers as: ${ }^{28}$

$$
\begin{aligned}
& \omega^{-}=\frac{\left(\mu^{-}\right)^{2}}{2 \eta}=\frac{\left(-\frac{1}{4}(3 I+A)\right)^{2}}{2(I-A)}=\frac{\left(\frac{1}{4}\left(3 \varepsilon_{H}+\varepsilon_{L}\right)\right)^{2}}{2\left(\varepsilon_{L}-\varepsilon_{H}\right)} \\
& \omega^{+}=\frac{\left(\mu^{+}\right)^{2}}{2 \eta}=\frac{\left(-\frac{1}{4}(I+3 A)\right)^{2}}{2(I-A)}=\frac{\left(\frac{1}{4}\left(\varepsilon_{H}+3 \varepsilon_{L}\right)\right)^{2}}{2\left(\varepsilon_{L}-\varepsilon_{H}\right)}
\end{aligned}
$$

\section{Local reactivity parameters}

Also, it is possible to analyze the chemical reactivity on different sites within a molecule employing local reactivity parameters. ${ }^{29,30}$ Probably, the Fukui Function $(f(r))$ is one of the local parameters most used to identify the more reactive regions or sites on a molecular system. ${ }^{31,32}$ The Fukui function (FF) is defined as: ${ }^{33}$

$$
f(r)=\left(\frac{\partial \rho(r)}{\partial N}\right)_{v(r)}=\left(\frac{\partial \mu(r)}{\partial v(r)}\right)
$$

where $\rho(r)$ is the electronic density. From equation (7), it is clear that FF indicates the regions where a chemical species will change its electronic density, when the number of electrons is modified, which is useful to identify the preferred either molecular regions, susceptible to electrophilic or nucleophilic attacks. ${ }^{29,33}$ In this sense, FF can be evaluated by using different approximations such as: a) frozen core approximation, b) finite differences, ${ }^{33} \mathrm{c}$ ) atomic charges,${ }^{34} \mathrm{~d}$ ) condensation of FMO to FF, ${ }^{35}$ and e) the dual descriptor, ${ }^{36}$ see Table 1.

\section{COMPUTATIONAL METHODOLOGY}

The optimal conformation of IND was subjected to full geometry optimization in the aqueous phase employing the $\mathrm{X} / 6-311++\mathrm{G}(2 \mathrm{~d}, 2 \mathrm{p})$ (where $\mathrm{X}=\mathrm{B} 3 \mathrm{LYP},{ }^{37,38} \mathrm{M} 06,{ }^{39} \mathrm{M}$ 06L, ${ }^{40}$ and $\mathrm{WB} 97 \mathrm{XD}^{41}$ ) level of theory, and the basis set $6-311++\mathrm{G}(2 \mathrm{~d}, 2 \mathrm{p}) \cdot{ }^{42,43}$ Solvent phase optimization were carried out using the polarizable continuum model (PCM) developed by Tomasi and coworkers. ${ }^{44,45}$ In all cases the vibrational frequencies were computed to make sure that the stationary points were minima in the potential energy surface (not shown). All the calculations reported here were performed with the package Gaussian $09,{ }^{46}$ and visualized with the GaussView V.3.09, ${ }^{47}$ packages.

\section{RESULTS AND DISCUSSION}

\section{Global reactivity parameters}

Figure 2 depicts the optimized structure of IND and its metabolites (ITI, ICA and FDAT) at the wB97XD/6-311++G(2d,2p) level of theory and in the aqueous phase, similar geometries were obtained at the other levels of theory analyzed in the present work. The global reactivity descriptors, for IND and its metabolites, evaluated through equations (1)-(6) are reported in Table 2, while the corresponding values, employing the Koopmans' theorem, are reported in Table 3. Considering that the stability order is given by the hardness value, from the values 
Table 1. Evaluation of the Fukui function following different approximations, for an electrophilic $\left(f^{-}(\mathrm{r})\right)$, nucleophilic $\left(f^{+}(\mathrm{r})\right)$ or free radical attack $\left(f^{0}(\mathrm{r})\right)$ on the reference molecule

\begin{tabular}{lc}
\hline Approximation & Equations \\
\hline & $f^{-}(r)=\varphi_{H}^{*}(r) \varphi_{H}(r)=\rho_{H}(r) \quad(8)$ \\
$f^{+}(r)=\varphi_{L}^{*}(r) \varphi_{L}(r)=\rho_{L}(r) \quad(9) \quad$ & $\rho_{H}(r)$ is the electronic density of the HOMO, \\
$\rho_{L}(r)$ is the electronic density of the LUMO.
\end{tabular}

$f(r)=\rho_{N}(r)-\rho_{N-l}(r)$
$f^{+}(r)=\rho_{N+l}(r)-\rho_{N}(r)$
$f^{0}(r)=1 / 2\left[\rho_{N+1}(r)-\rho_{N-l}(r)\right]$

b) Finite difference approximation ${ }^{33}$

$f^{0}(r)=1 / 2\left[\rho_{N+1}(r)-\rho_{N-l}(r)\right] \quad(12)$

$\rho_{N+1}(r), \rho_{N}(r)$ and $\rho_{N-1}(r)$ correspond to the electronic density of the anion, neutral and cationic chemical species.

c) Condensed Atomic Fukui function employing atomic charges. ${ }^{34}$

d) Condensation of Frontier Molecular Orbital to the Fukui Function. ${ }^{35}$

$f_{j}^{-}(r)=q_{j(N-l)}-q_{j(N)}$
$f_{j}^{+}(r)=q_{j(N)}-q_{j(N+l)}$
$f_{j}^{0}(r)=1 / 2\left(q_{j(N-l)}-q_{j(N+l)}\right.$

$f_{j}^{+}(r)=q_{j(N)}-q_{j(N+l)}$
$f_{j}^{0}(r)=1 / 2\left(q_{j(N-l)}-q_{j(N+l)}\right.$

$q_{j}$ is the atomic charge at the $j_{\mathrm{th}}$ atomic site in the neutral $(N)$, anionic $(N+1)$ or cationic $(N-1)$ chemical species

\section{$f_{\propto}^{\infty}=\sum v \mu c_{\mu h(l)}^{*} c_{v h(l)} S_{\mu v} \quad(16)$}

$S_{\mu v}$ is the overlap integral between the atomic orbitals $\chi_{\mu}(\mathrm{r})$ and $\chi_{v}(\mathrm{r})$, while $c_{\mathrm{vh}}(1)$ is the $v_{\text {th }}$ expansion coefficient for HOMO (h) or LUMO (l), and $\alpha=-,+$.

e) Dual descriptor ${ }^{36}$
$f^{2}(r) \approx f^{+}(r)-f(r)=\rho_{N+1}(r)-2 \rho_{N}(r)+\rho_{N-I}(r) \quad(17)$
nucleophilic attacks $f^{2}(r)>0$
electrophilic attacks $f^{2}(r)>0$

reported in these tables, it is clear that in all cases, this order is FDAT $>$ IND $>$ ICA $>$ ITI, suggesting that ITI is the more reactive compound of this set of molecules. Also, note that the values of $\mu$ are lower for ITI and ICA in comparison to IND and FDAT, which is indicative that ITI and ICA are less electrophilic. On the other hand, the lower values of $\omega$ for IND and FDAT indicates a less propensity to accept electrons in comparison to ITI and ICA. Here, it is interesting to mention that some authors suggest that the origin of the toxicity of some molecules may be attributed to the electron accepting nature. ${ }^{48}$ In this sense, the descriptor $\omega^{+}$might be able to predict the toxicity of a molecular system. ${ }^{49}$ It has been reported that this approximation has been useful to predict the toxicity of dioxins, ${ }^{50,51}$ and derivatives of benzidine. ${ }^{52}$ If ones applies this approximation to IND and its metabolites, the toxicity order is ITI $>$ ICA $>$ FDAT $>$ IND . Nevertheless, the EPA has not found indaziflam to share a common mechanism of toxicity with any other substances, and IND does not appear to yield a toxic metabolite produced by other substances. ${ }^{53}$ On the other hand, the indaziflam ecotoxicity descriptor measured through $\mathrm{EC}_{50}$ (median effective concentration) in Lemna giba (vascular) plant indicates that the ecotoxicity order is ICA > FDAT > ITI $>$ IND.${ }^{54}$ Note that these results are different to those predicted by $\omega^{+}$. Moreover, the other global chemical descriptors reported in Tables 2 and 3 were not able to predict the toxicity order reported in the literature, which suggests that equation (6) cannot be used, in general, to evaluate the toxicity of a chemical compound. However, due to the a)

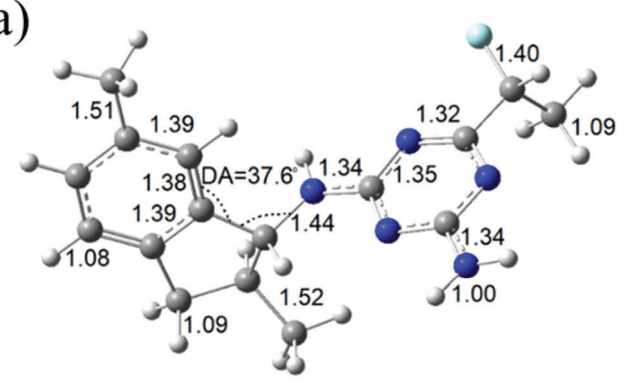

c)

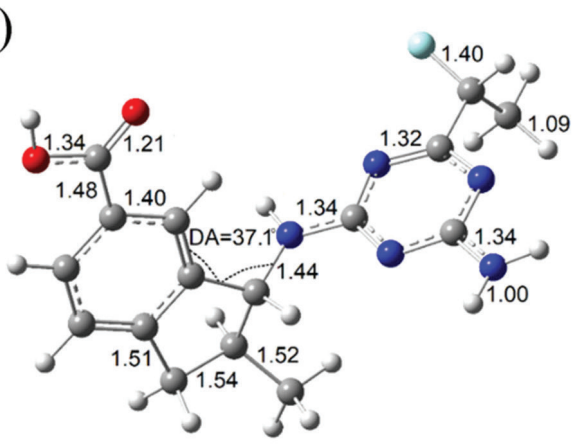

b)

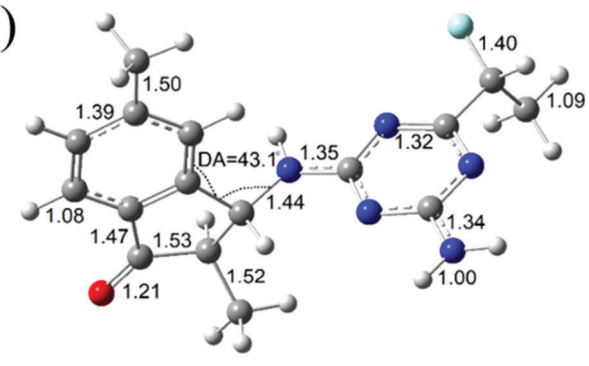

d)

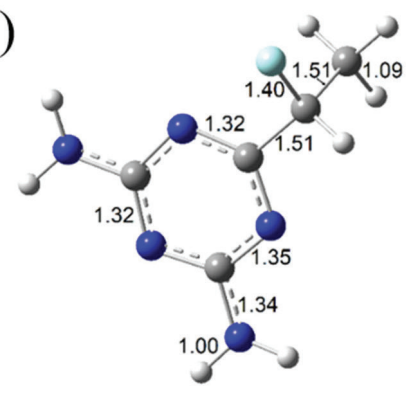

Figure 2. Chemical structures of a) IND, b) ITI, c) ICA and d) FDAT optimized at the $w B 97 X D / 6-311++G(2 d, 2 p)$ level of theory in the aqueous phase employing the PCM solvation model. Bond distances are given in Angstroms, DA=Dihedral Angle 
different mechanisms of toxicity and the lacking information related to the toxicity of IND, more theoretical and experimental studies are required to evaluate the potential toxicity of indaziflam under laboratory and field conditions. ${ }^{14}$ Here, it is important to highlight that to analyze the toxicity of IND and its metabolites is beyond of the main scope of this paper.

Table 2. Global reactivity parameters evaluated at the X/6-311++G(2d,2p) (where X=B3LYP, M06, M06L and WB97XD) level of theory and in the aqueous phase, employing equations (1)-(6)

\begin{tabular}{|c|c|c|c|c|c|c|c|c|}
\hline & $I / \mathrm{eV}$ & $A / \mathrm{eV}$ & $\mu / \mathrm{eV}$ & $\eta / \mathrm{eV}$ & $\chi / \mathrm{eV}$ & $\omega / \mathrm{eV}$ & $\omega^{+} / \mathrm{eV}$ & $\omega^{-} / \mathrm{eV}$ \\
\hline \multicolumn{9}{|l|}{ IND } \\
\hline B3LYP & 6.37 & 1.19 & -3.78 & 5.18 & 3.78 & 1.38 & 0.60 & 2.49 \\
\hline M06 & 6.41 & 1.16 & -3.79 & 5.25 & 3.79 & 1.37 & 0.58 & 2.48 \\
\hline M06L & 6.11 & 1.05 & -3.58 & 5.06 & 3.58 & 1.27 & 0.53 & 2.32 \\
\hline WB97XD & 6.50 & 1.02 & -3.76 & 5.48 & 3.76 & 1.29 & 0.52 & 2.40 \\
\hline \multicolumn{9}{|l|}{ ITI } \\
\hline B3LYP & 6.62 & 2.10 & -4.36 & 4.51 & 4.36 & 2.11 & 1.16 & 3.34 \\
\hline M06 & 6.84 & 2.11 & -4.48 & 4.73 & 4.48 & 2.12 & 1.15 & 3.39 \\
\hline M06L & 6.29 & 2.02 & -4.15 & 4.27 & 4.15 & 2.02 & 1.11 & 3.19 \\
\hline WB97XD & 6.92 & 1.96 & -4.44 & 4.96 & 4.44 & 1.99 & 1.03 & 3.25 \\
\hline \multicolumn{9}{|l|}{ ICA } \\
\hline B3LYP & 6.61 & 1.92 & -4.26 & 4.70 & 4.26 & 1.94 & 1.02 & 3.15 \\
\hline M06 & 6.79 & 1.91 & -4.35 & 4.88 & 4.35 & 1.94 & 1.01 & 3.18 \\
\hline M06L & 6.35 & 1.81 & -4.08 & 4.54 & 4.08 & 1.83 & 0.95 & 2.99 \\
\hline WB97XD & 6.84 & 1.76 & -4.30 & 5.08 & 4.30 & 1.82 & 0.91 & 3.06 \\
\hline \multicolumn{9}{|l|}{ FDAT } \\
\hline B3LYP & 6.99 & 1.26 & -4.13 & 5.74 & 4.13 & 1.48 & 0.63 & 2.69 \\
\hline M06 & 7.16 & 1.20 & -4.18 & 5.95 & 4.18 & 1.47 & 0.61 & 2.70 \\
\hline M06L & 6.85 & 1.02 & -3.94 & 5.83 & 3.94 & 1.33 & 0.53 & 2.50 \\
\hline WB97XD & 7.16 & 1.08 & -4.12 & 6.08 & 4.12 & 1.40 & 0.56 & 2.62 \\
\hline
\end{tabular}

Table 3. Global reactivity parameters evaluated at the X/6-311++G(2d,2p) (where X=B3LYP, M06, M06L and WB97XD) level of theory and in the aqueous phase, employing the equations (1)-(6) and the Koopmans's theorem

\begin{tabular}{|c|c|c|c|c|c|c|c|c|}
\hline & $I / \mathrm{eV}$ & $A / \mathrm{eV}$ & $\mu / \mathrm{eV}$ & $\eta / \mathrm{eV}$ & $\chi / \mathrm{eV}$ & $\omega / \mathrm{eV}$ & $\omega^{+} / \mathrm{eV}$ & $\omega / \mathrm{eV}$ \\
\hline \multicolumn{9}{|l|}{ IND } \\
\hline B3LYP & 6.49 & 1.05 & -3.77 & 5.44 & 3.77 & 1.31 & 0.53 & 2.42 \\
\hline M06 & 6.76 & 1.12 & -3.94 & 5.65 & 3.94 & 1.37 & 0.57 & 2.54 \\
\hline M06L & 5.78 & 1.42 & -3.60 & 4.36 & 3.60 & 1.49 & 0.72 & 2.52 \\
\hline WB97XD & 8.44 & -0.97 & -3.73 & 9.41 & 3.73 & 0.74 & 0.10 & 1.97 \\
\hline \multicolumn{9}{|l|}{ ITI } \\
\hline B3LYP & 6.74 & 1.96 & -4.35 & 4.78 & 4.35 & 1.98 & 1.04 & 3.22 \\
\hline M06 & 7.12 & 1.76 & -4.44 & 5.36 & 4.44 & 1.84 & 0.90 & 3.12 \\
\hline M06L & 5.88 & 2.41 & -4.14 & 3.47 & 4.14 & 2.47 & 1.54 & 3.62 \\
\hline WB97XD & 8.75 & 0.05 & -4.40 & 8.70 & 4.40 & 1.11 & 0.29 & 2.49 \\
\hline \multicolumn{9}{|l|}{ ICA } \\
\hline B3LYP & 6.74 & 1.78 & -4.26 & 4.96 & 4.26 & 1.83 & 0.92 & 3.05 \\
\hline M06 & 7.10 & 1.58 & -4.34 & 5.52 & 4.34 & 1.70 & 0.79 & 2.96 \\
\hline M06L & 5.96 & 2.22 & -4.09 & 3.74 & 4.09 & 2.23 & 1.33 & 3.37 \\
\hline WB97XD & 8.70 & -0.15 & -4.28 & 8.85 & 4.28 & 1.03 & 0.24 & 2.38 \\
\hline \multicolumn{9}{|l|}{ FDAT } \\
\hline B3LYP & 7.09 & 1.12 & -4.11 & 5.97 & 4.11 & 1.41 & 0.57 & 2.63 \\
\hline M06 & 7.49 & 1.04 & -4.26 & 6.44 & 4.26 & 1.41 & 0.55 & 2.68 \\
\hline M06L & 6.34 & 1.49 & -3.91 & 4.84 & 3.91 & 1.58 & 0.76 & 2.71 \\
\hline WB97XD & 9.11 & -0.93 & -4.09 & 10.04 & 4.09 & 0.83 & 0.12 & 2.17 \\
\hline
\end{tabular}




\section{Local reactivity parameters}

In order to determine the more reactive regions of IND and its metabolites we used the Frozen core and the finite difference approximations. ${ }^{33}$ Figure 3 , shows the distribution of the electrophilic sites on IND and its metabolites, within the frozen core approximation. ${ }^{33}$ In all cases, it may be observed an extended HOMO's distribution in the whole molecule, except on the fluoroethyl group, see Figure 3. In the case of nucleophilic sites for IND, the region where the LUMO attains its larger values is on the triazine zone. For ITI and ICA, LUMO's distributions are located on the indene region, while in FDAT is completely extended on the triazine ring.

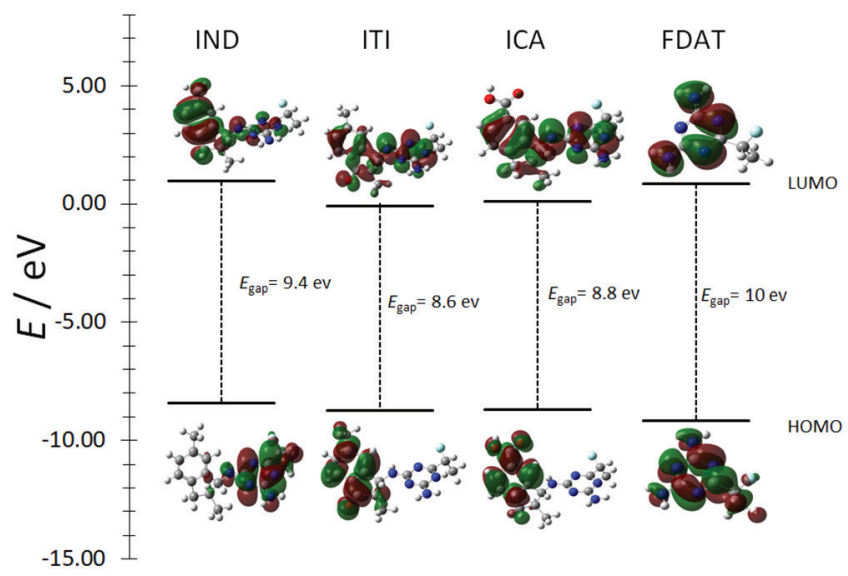

Figure 3. HOMO and LUMO's distributions on IND, ITI, ICA and FDAT obtained at the $w B 97 X D / 6-311++G(2 d, 2 p)$ level of theory in the aqueous phase employing the PCM solvation model. In all cases the isosurfaces were obtained at $0.08 \mathrm{e} / \mathrm{u} \cdot \mathrm{a}^{3}$

The determination of the more reactive regions, employing the finite difference approximation and defined by equations (10)-(12), are depicted in Figures 4, 5, 6 and 7 for IND, ITI, ICA and FDAT respectively. In the case of an electrophilic attack, IND exhibits the more reactive sites on the benzene ring, while ITI and ICA on the nitrogen atom of the central section of the molecule. In the case of FDAT the more electrophilic active sites are located on the nitrogen atoms. For nucleophilic attacks the more reactive sites for IND are observed on the carbon atoms of triazine, for ITI on the carbonyl group, in the case of ICA the more reactive zone is the carboxylic group, and for FDAT the nitrogen atoms of triazine. For the case of free radical attacks, the more reactive sites for IND are located on the benzene and triazine rings, for ITI, on the carbonyl group, on the nitrogen atom of the central section of the molecule, and nitrogen atoms of triazine. For ICA on the carboxylic group and nitrogen atom of the central section, while that for FDTA, nitrogen atoms of triazine ring are the more reactive zones. Last results suggest that electrophilic and free radical attacks may cleave the $\mathrm{N}$ bond located in the central section of ITI and ICA to form FDAT, which is agree with the available experimental results. ${ }^{8}$

Note, that from the FMO and finite difference approximations is possible to identify the more reactive regions on IND and its metabolites, see Figures 3-7. However, CFF is more adequate to determine the more reactive sites or atoms on a molecular system. Thus, the higher values of CFF allow identifying the more reactive atoms in the molecule of reference. Through equations (13)-(15) and (16), it is possible to condense the value of FF in each atom to determine the pinpoint distribution of the reactive sites on the molecular system. In the case of equations (13)-(15), we used the Hirshfeld population to evaluate the values of CFF because the values obtained are non-negative. ${ }^{30,55}$ The values of CFF, employing Hirshfeld population, for IND are depicted in Figures 8, 9 and 10 for electrophilic, nucleophilic and free radical attacks, respectively. Figure 8 shows, the distribution of the active sites on IND employing the X/6-311++G(2d,2p) (where X=B3LYP, M06, M06L and WB97XD) level of theory. Note that the calculations at the different levels of theory are predicting the same more reactive sites for electrophilic a)

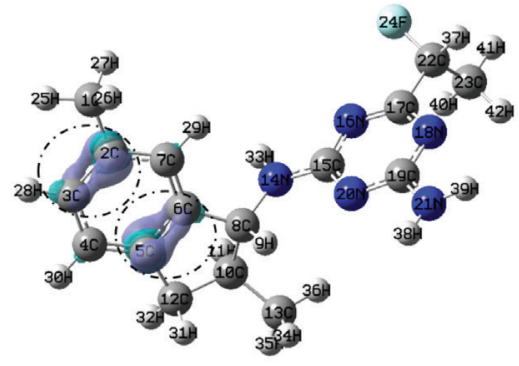

b)

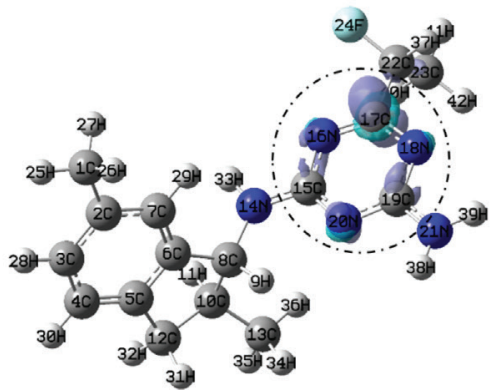

c)

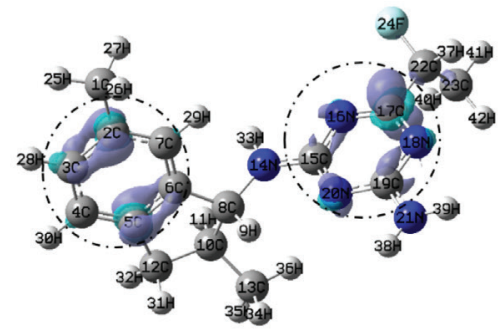

Figure 4. Isosurfaces of the Fukui Functions for IND according to equations (10), (11) and (12) at the wB97XD/6-311++G(2d,2p) level of theory employing the PCM solvation model. In the case of (a) electrophilic, $b$ ) nucleophilic and c) free radical attacks. In all cases the isosurfaces were obtained at 0.008 e/u.a. ${ }^{3}$, broken circles show the more reactive zones in each molecule

a)

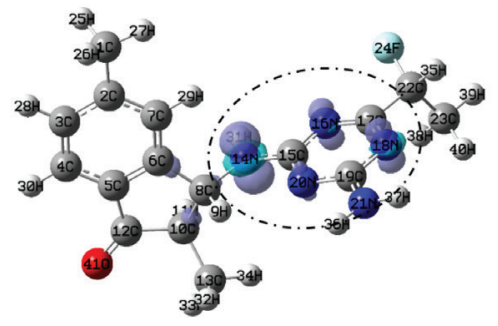

b)

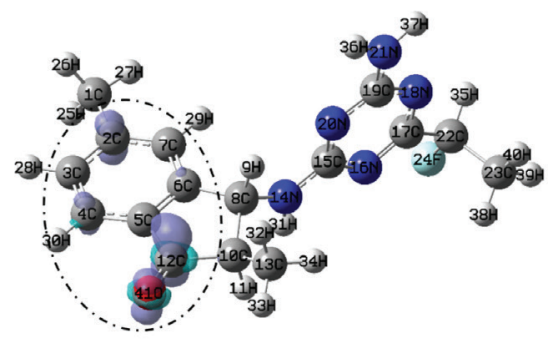

c)

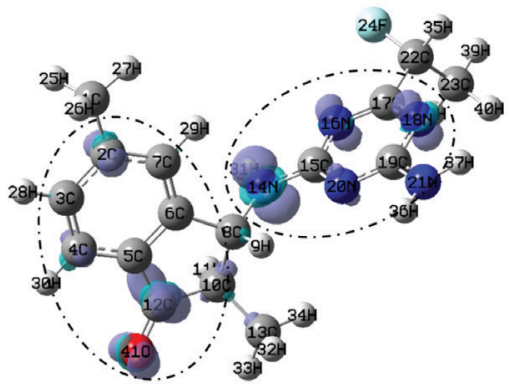

Figure 5. Isosurfaces of the Fukui Functions for ITI according to equations (10), (11) and (12) at the wB97XD/6-311++G(2d,2p) level of theory employing the PCM solvation model. In the case of (a) electrophilic, b) nucleophilic and c) free radical attacks. In all cases the isosurfaces were obtained at 0.008 e/u.a. ${ }^{3}$, broken circles show the more reactive zones in each molecule 
a)

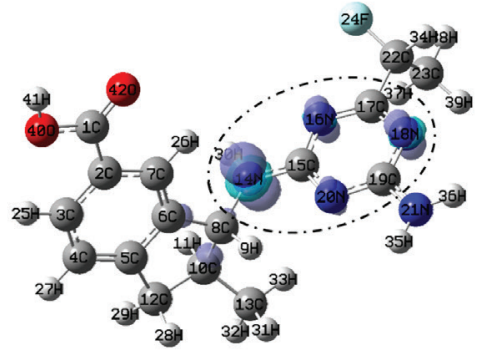

b)

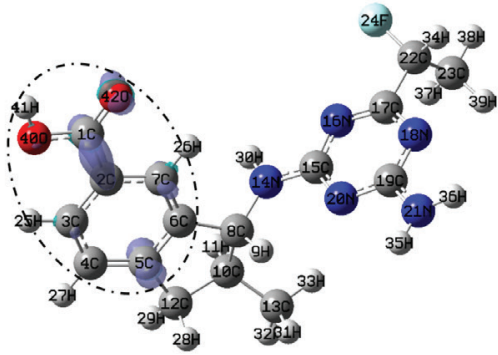

c)

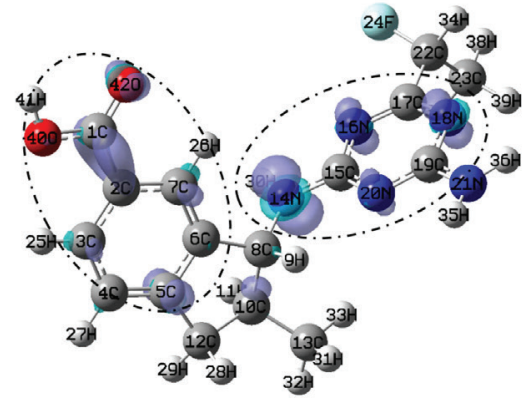

Figure 6. Isosurfaces of the Fukui Functions for ICA according to equations (10), (11) and (12) at the wB97XD/6-311++G(2d,2p) level of theory employing the PCM solvation model. In the case of (a) electrophilic, b) nucleophilic and c) free radical attacks. In all cases the isosurfaces were obtained at 0.008 e/u. ${ }^{3}$, broken circles show the more reactive zones in each molecule

a)

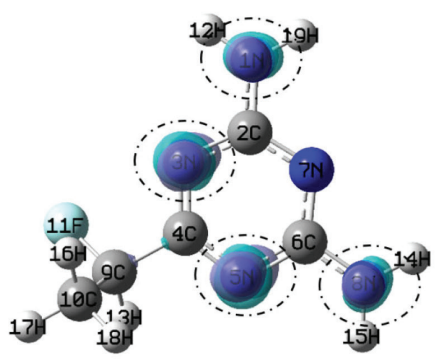

b)

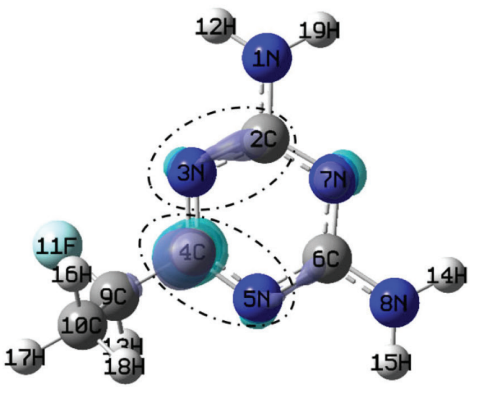

c)

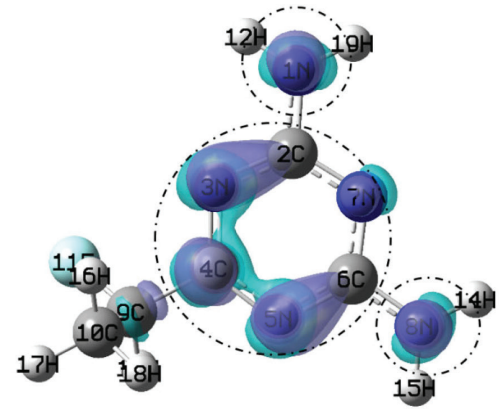

Figure 7. Isosurfaces of the Fukui Functions for FDAT according to equations (10), (11) and (12) at the wB97XD/6-311++G(2d,2p) level of theory employing the PCM solvation model In the case of (a) electrophilic, b) nucleophilic and c) free radical attacks. In all cases the isosurfaces were obtained at 0.008 e/u.a. ${ }^{3}$, broken circles show the more reactive zones in each molecule

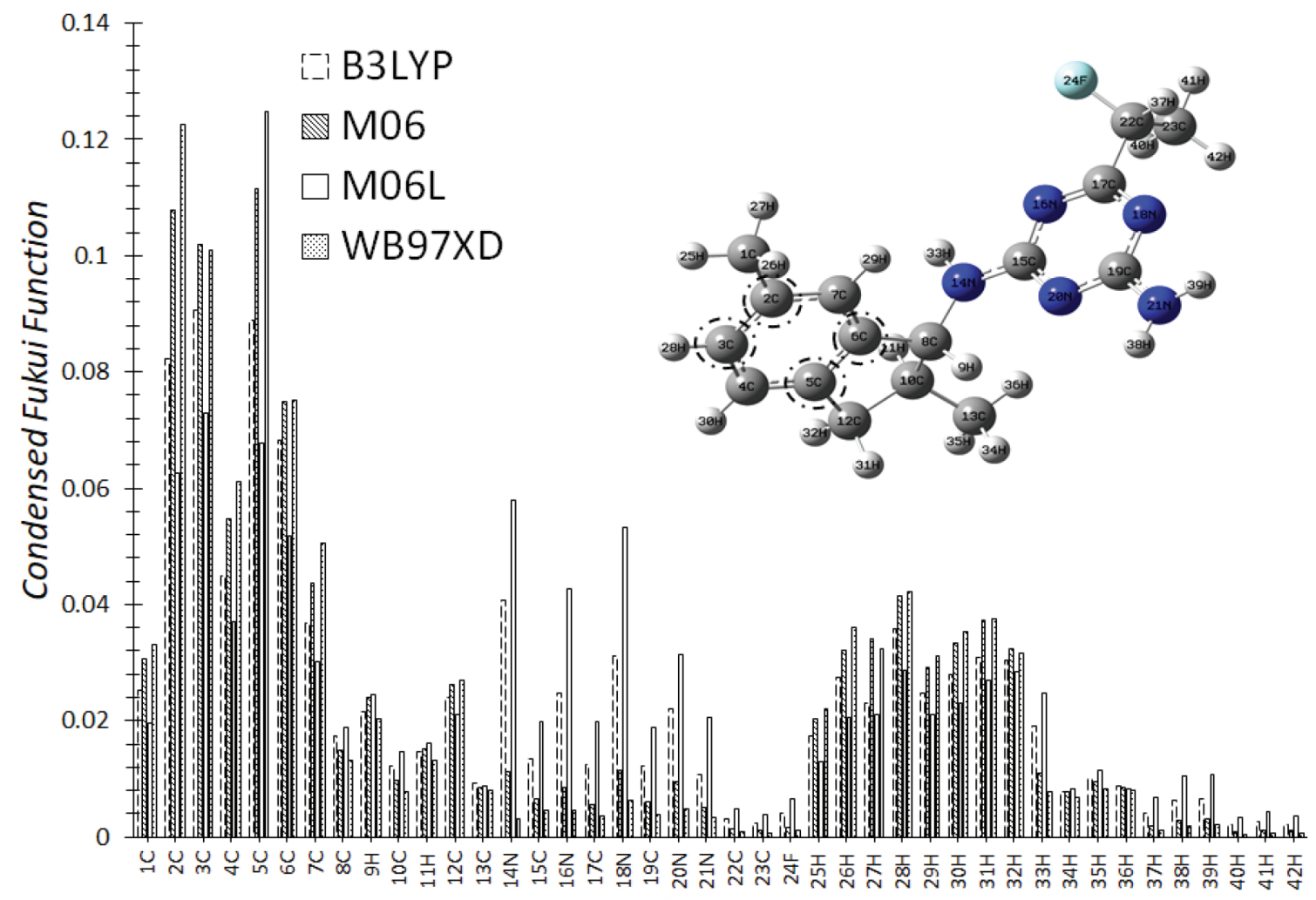

Atom

Figure 8. Condensed Fukui Function values for electrophilic attacks on IND at the X/6-311++G (2d,2p) (where X=B3LYP, M06, M06L and WB97XD) level of theory, in the aqueous phase employing Hirshfeld population and equations (13)-(15), broken circles show the more reactive zones in each molecule 


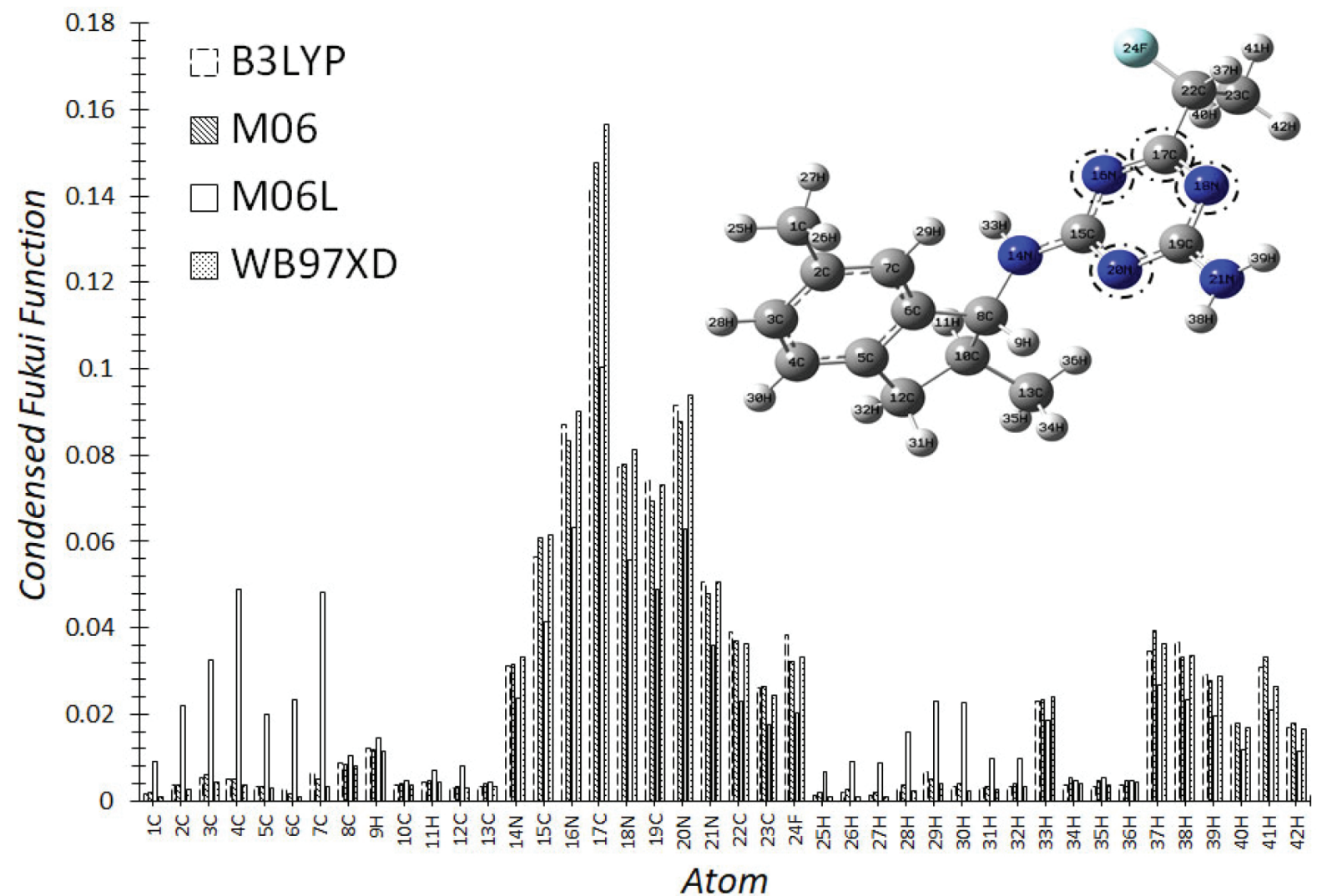

Figure 9. Condensed Fukui Function values for nucleophilic attacks on IND at the X/6-311++G $(2 d, 2 p)$ (where X=B3LYP, M06, M06L and WB97XD) level of theory, in the aqueous phase employing Hirshfeld population and equations (13)-(15), broken circles show the more reactive zones in each molecule

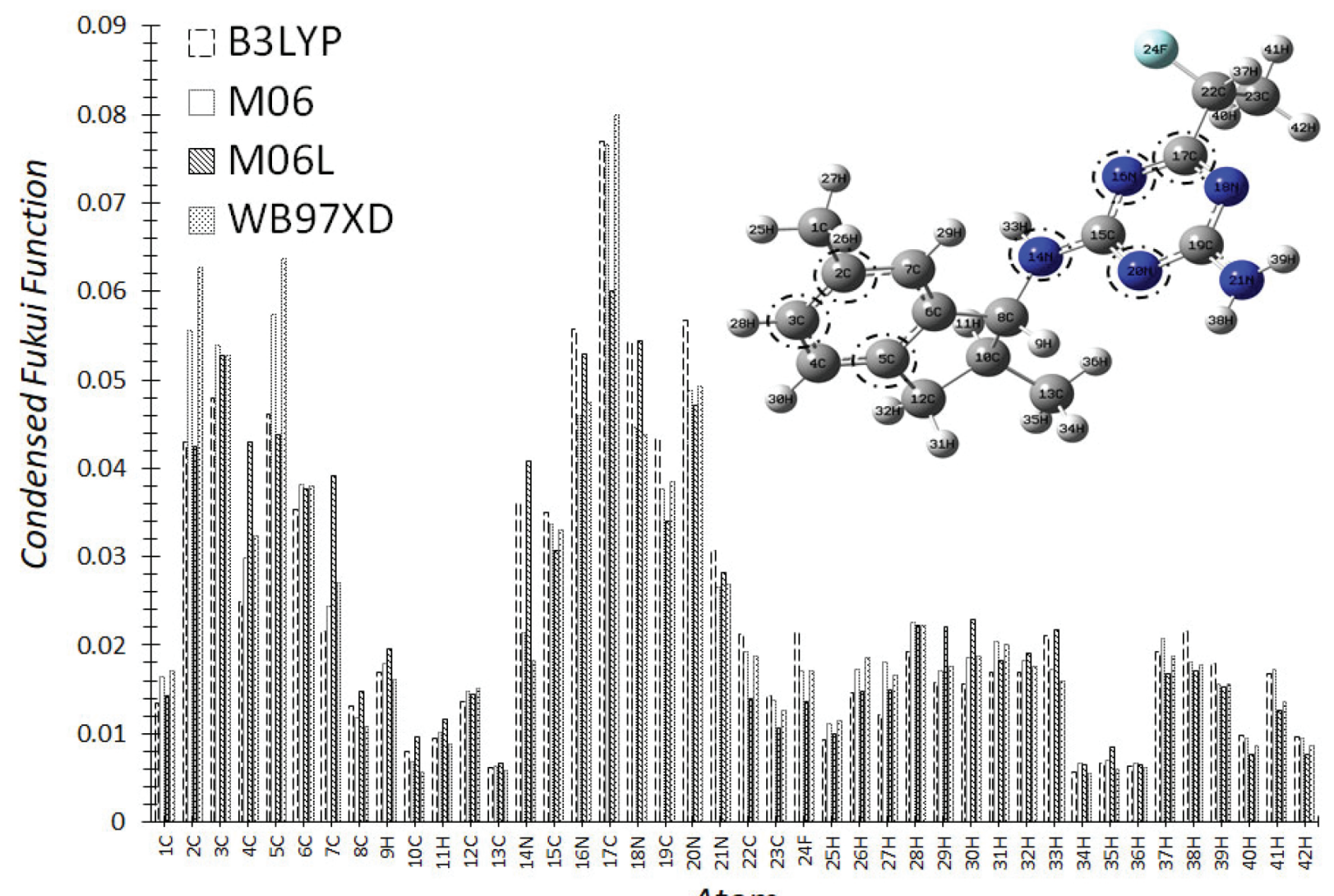

Figure 10. Condensed Fukui Function values for free radical attacks on IND at the X/6-311++G $(2 d, 2 p)$ (where X=B3LYP, M06, M06L and WB97XD) level of theory, in the aqueous phase employing Hirshfeld population and equations (13)-(15), broken circles show the more reactive zones in each molecule 
attacks and they are placed on the atoms $2 \mathrm{C}, 3 \mathrm{C}, 5 \mathrm{C}$ and $6 \mathrm{C}$, located on the benzene ring. For the case of nucleophilic attacks, see Figure 9, the more reactive sites are located on $17 \mathrm{C}, 16 \mathrm{~N}$ and $20 \mathrm{~N}$, and in the free radical case, see Figure 10, the more reactive sites are located on $17 \mathrm{C}, 5 \mathrm{C}, 2 \mathrm{C}$ and $3 \mathrm{C}$. Note that these results are coincident with those derived from equations (10)-(12)), see Figures 4-7.

Also, we evaluated the values of CFF through equation (16) and employing the frontier molecular orbitals HOMO and LUMO, however we obtained negative values for $\mathrm{CFF}$, which has not physical meaning. In this sense, it has been reported that equation (16) is quite reliable and stable when is calculated with small basis sets, but is not able to predict the correct values when diffuse functions are employed.$^{56}$ However, diffuse functions are generally required to investigate nucleophilic susceptibilities. ${ }^{56}$ Therefore, we employed only the equations, (13)-(15) to evaluate the values of CFF of IND and its metabolites. Similar analysis to those reported in Figures 8-10, are reported, as supplementary material, for ITI, ICA and FDAT metabolites, see Figures 1S-9S in supplementary material. In Table 4, it is presented a summary of the more reactive sites for the molecules analyzed in the present work, considering different levels of theory and approximations to evaluate $\mathrm{FF}$ and $\mathrm{CFF}$ values.

In addition, we analyzed the local chemical reactivity of IND and its metabolites by mean the dual descriptor, ${ }^{36}$ equation (17). This descriptor allows us to obtain simultaneously the preferably sites for nucleophilic and electrophilic attacks on the system. ${ }^{36}$ In Figure 11 is reported the distribution of the dual descriptor for IND and its metabolites. Note that the more nucleophilic and electrophilic active sites for IND and its metabolites are coincident with those reported in Table 4.

Additional to the global and local reactivity descriptors it is possible to analyze the chemical reactivity through maps of the
Table 4. More reactive sites obtained for IND and its metabolites employing different levels of theory, and approximations to evaluate the Fukui function. Atomic labels are reported in Figures 4-7

\begin{tabular}{lccc}
\hline & $f^{-}(r)$ & $f^{+}(r)$ & $f^{0}(r)$ \\
\hline IND & $\begin{array}{c}5 \mathrm{C}, 2 \mathrm{C}, 3 \mathrm{C} \\
\text { and 6C }\end{array}$ & $\begin{array}{c}17 \mathrm{C}, 20 \mathrm{~N}, 16 \mathrm{~N} \\
\text { and 18N }\end{array}$ & $\begin{array}{c}17 \mathrm{C}, 5 \mathrm{C}, 2 \mathrm{C} \\
\text { and 3C }\end{array}$ \\
\hline ITI & $\begin{array}{c}14 \mathrm{~N}, 18 \mathrm{~N}, 16 \mathrm{~N} \\
\text { and 20N }\end{array}$ & $\begin{array}{c}41 \mathrm{O}, 12 \mathrm{C}, 2 \mathrm{C} \\
\text { and 4C }\end{array}$ & $\begin{array}{c}41 \mathrm{O}, 12 \mathrm{C}, 14 \mathrm{~N} \\
\text { and 4C }\end{array}$ \\
\hline \multirow{2}{*}{ ICA } & $\begin{array}{c}14 \mathrm{~N}, 18 \mathrm{~N}, 16 \mathrm{~N} \\
\text { and 20N }\end{array}$ & $\begin{array}{c}42 \mathrm{O}, 1 \mathrm{C}, 5 \mathrm{C} \\
\text { and 7C }\end{array}$ & $\begin{array}{c}14 \mathrm{~N}, 42 \mathrm{O}, 1 \mathrm{C} \\
\text { and 5C }\end{array}$ \\
\hline \multirow{2}{*}{ FDAT } & $5 \mathrm{~N}, 3 \mathrm{~N}, 1 \mathrm{~N}$ & $4 \mathrm{C}, 7 \mathrm{~N}, 5 \mathrm{~N}$ & $5 \mathrm{~N}, 3 \mathrm{~N}, 4 \mathrm{C}$ \\
& and 8N & and 3N & and 1N \\
\hline
\end{tabular}

molecular electrostatic potential (MEP). ${ }^{57}$ In Figure 12 are depicted the MEP for IND and its metabolites ITI, ICA and FDAT. In these images, areas of negative potential (red color), are characterized by an abundance of electrons while areas of positive potential (blue color), are characterized by a relative lack of electrons. In the case of IND and FDAT the nitrogen atoms exhibit the lowest values of potential in comparison to the other atoms; consequently have a higher electron density around it, ITI and ICA shows that the nitrogen and oxygen atoms as the places with the lowest potential and therefore they are the more electrophilic active sites.

\section{CONCLUSIONS}

In the present work, we analyzed the chemical reactivity of indaziflam and its metabolites in the aqueous phase. Considering a)

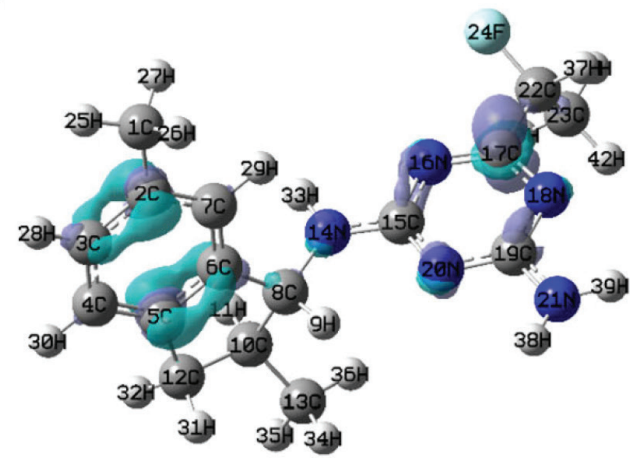

c)

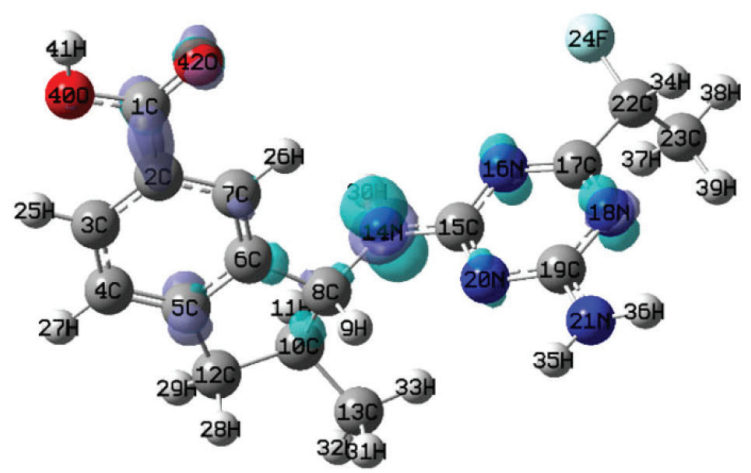

b)

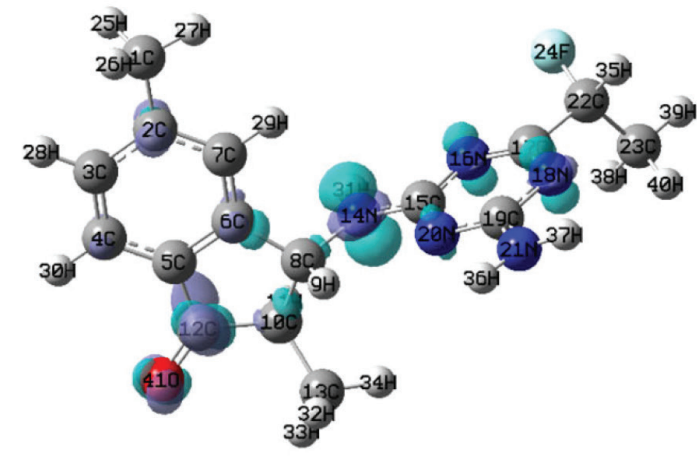

d)

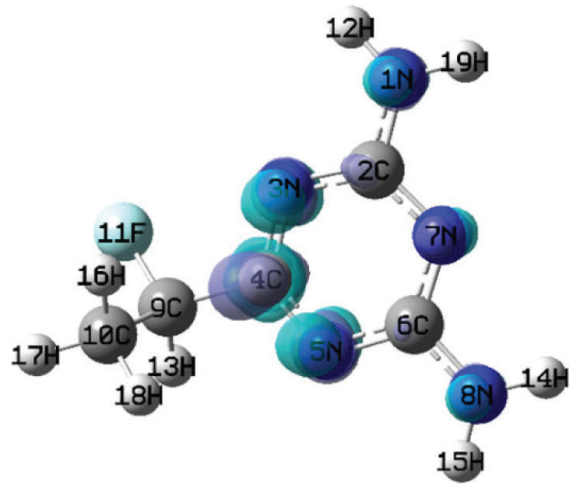

Figure 11. Dual descriptors evaluated at the $w B 97 X D / 6-311++G(2 d, 2 p)$ level of theory employing the PCM solvation model according to equation (17). In all cases, the isosurfaces were obtained at 0.008 e/u.a. ${ }^{3}$ a). IND, b) ITI, c) ICA and d) FDAT 
a) IND

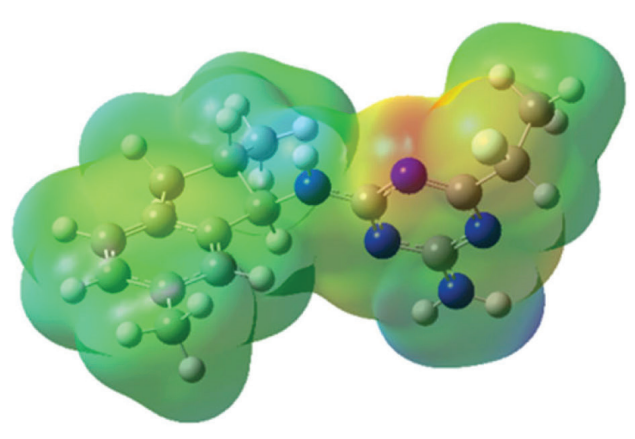

c) ICA

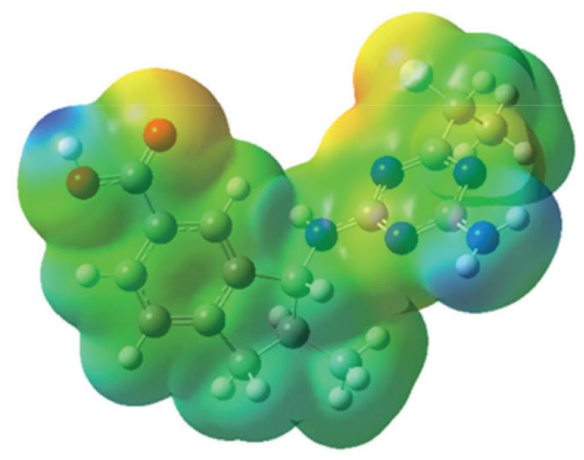

b) ITI

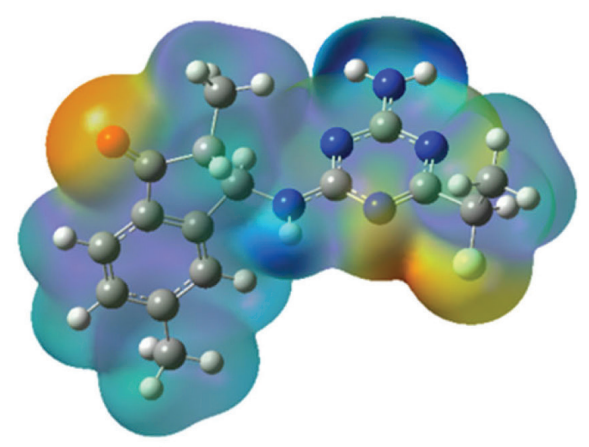

d) FDAT

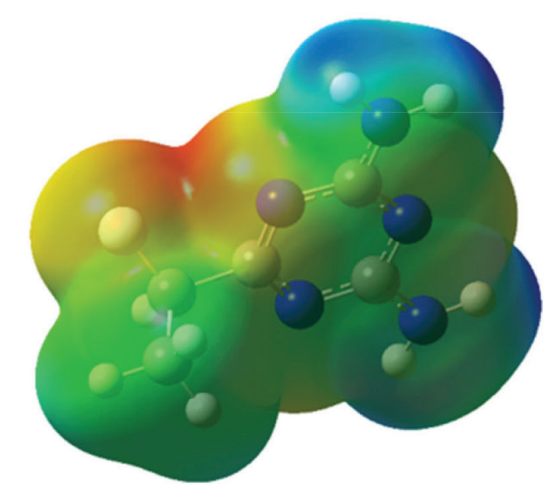

Figure 12. Mapping of the electrostatic potentials evaluated at the $w B 97 X D / 6-311++G(2 d, 2 p)$ level of theory employing the PCM solvation model, onto a density isosurface (value $=0.002$ ela.u. ${ }^{3}$ ) for a) IND, b) ITI, c) ICA, and d) FDAT

the hardness values, ITI is the more reactive compound, followed by ICA, IND and FDAT. ITI and ICA are the metabolites with lower electrophilic behavior in comparison to IND and FDAT. Employing different levels of theory and approximations the results indicate that for IND, the more reactive sites for electrophilic attacks are located on the carbon atoms of the aromatic ring. For ITI and ICA are located on the nitrogen atom of the central section, and on the nitrogen atoms of amines for FDAT. In the nucleophilic case, carbon atoms on triazine rings, carbonyl group, carboxylic group, and nitrogen atoms of triazine, for IND, ITI, ICA and FDAT, respectively, are the more reactive sites. Finally, the more reactive sites for the case of free radical attacks, are located on the benzene and triazine rings for IND; on the carbonyl group, nitrogen atom of the central section, and nitrogen atoms of triazine for ITI. For ICA on the carboxylic group and nitrogen atom of the central section, while that for FDAT the more reactive sites are located on the nitrogen atoms of triazine ring.

\section{SUPPLEMENTARY MATERIAL}

Figure 1S-9S can be found at http://quimicanova.sbq.org.br in PDF format, with free access.

\section{ACKNOWLEDGEMENTS}

LHMH gratefully acknowledges financial support from CONACYT (project CB2015-257823) and to the Universidad Autónoma del Estado de Hidalgo. Guanajuato National Laboratory (CONACyT 123732) is acknowledged for supercomputing resources.
LHMH acknowledges to the SNI for the distinction of his membership and the stipend received.

\section{REFERENCES}

1. Myers, D.; Hanrahan, R.; Michel, J.; Monke, B.; Mudge, L.; Olsen, C.; Parker, A.; Smith, J.; Spak, D.; Proc. South Weed Sci. Soc. 2009, 62, 393.

2. Kaapro, J.; Hall, L.; Pak. J. Weed Sci. Res. 2012, 18, 267.

3. Guerra, N.; Silvério de Oliveira, R.; Constantin, J.; Mendes de Oliveira, A.; Braga, G.; Revista Brasileira de Herbicidas 2013, 12, 285.

4. Brabham, C.; Lei, L.; Gu, Y.; Stork, J.; Barrett, M.; DeBolt, S.; Plant Physiol. 2014, 166, 1177.

5. Jhala, A. J.; Ramirez, A. H. M.; Singh, M.; Bull. Environ. Contam. Toxicol. 2012, 88, 326.

6. http://www.epa.gov/pesticides/chem_search/reg_actions/registration/ fs_PC-080818_26-Jul-10.pdf, accessed June 2019.

7. Sebastian, D. J.; Nissen, S. J.; Westra, P.; Shaner, D. L.; Butters, G.; Pest. Manage. Sci. 2017, 73, 444.

8. Jhala, A.J.; Singh, M.; Weed Tech. 2012, 26, 602.

9. Trigo, C.; Koskinen, W. C.; Kookana, R. S.; J. Environ. Sci. Health, Part B 2014, 49, 836.

10. Alonso, D. G.; de Oliveira, R. S.; Koskinen, W. C.; Hall, K.; Constantin, J.; Mislankar, S.; Sci. Agric. 2016, 73, 169.

11. Prata, F.; Lavorenti, A.; Borges, J.; Tornisielo, V. L.; Pesq. Agropec. Bras. 2001, 36, 975.

12. Guerra, N., Oliveira, R. S.; Constantine, J.; Oliveira, A. M.; Gemeli, A.; Pereira, D. M.; Guerra, A.; Planta Daninha 2016, 34, 345.

13. González-Delgado, A. M.; Shukla, M. K.; Ashigh, J.; Perkins, R.; J. Environ. Sci. 2017, 51, 111. 
14. González-Delgado, A. M.; Ashigh, J.; Shukla, M. K.; Perkins, R.; PLoS One 2015, 10, e0126100.

15. Alonso, D. G.; Koskinen, W. C.; Oliveira, R. S.; Constantin, J.; Mislankar, S.; J. Agric. Food Chem. 2011, 59, 13096.

16. Alonso, D. G.; Oliveira, R. S.; Hall, K. E.; Koskinen, W. C.; Constantin, J.; Mislankar, S.; Geoderma 2015, 239-240, 250.

17. Gázquez, J. L.; J. Mex. Chem. Soc. 2008, 52, 3.

18. Geerlings, P.; De Proft, F.; Langenaeker, W.; Chem. Rev. 2003, 103, 1793.

19. Parr, R. G.; Pearson, R. G.; J. Am. Chem. Soc. 1983, 105, 7512.

20. Pearson, R. G.; J. Chem. Educ. 1987, 64, 561.

21. Parr, R. G.; Chattaraj, P. K.; J. Am. Chem. Soc. 1991, 113, 1854.

22. Pearson, R. G.; J. Am. Chem. Soc. 1985, 107, 6801.

23. Adejoro, I. A.; Odiaka, T. I.; Akinyele, O. F.; J. Nat. Sci. Res. 2014, 4, 38.

24. Ruiz-Anchondo, T.; Flores-Holguín, N.; Glossman-Mitnik, D.; Molecules 2010, 15, 4490.

25. Vektariene, A.; Vektaris, G.; Svoboda, J.; Arkivoc 2009, VII, 311.

26. Parr, R.; Donnelly, R. A.; Levy, M.; Palke, W. E.; J. Chem. Phys. 1978, 68, 3801.

27. Pearson, R. G.; J. Chem. Educ. 1987, 64, 561.

28. Parr, R. G.; Szentpaly, L.; Liu, S.; J. Am. Chem. Soc. 1999, 121, 1922.

29. Parr, R. G.; Yang, W.; Density Functional Theory of Atoms and Molecules, $1^{\text {st }}$ ed., Oxford University Press: New York, 1989.

30. Liu, S. B., In Chemical Reactivity Theory: A Density Functional View; Chattaraj, P. K., ed.; Taylor and Francis: Boca Raton, 2009.

31. Gazquez, J. L.; Mendez, F.; J. Phys. Chem. 1994, 98, 4591.

32. Mendez, F., Gazquez, J. L.; J. Am. Chem. Soc. 1994, 116, 9298.

33. Parr, R. G.; Yang, W.; J. Am. Chem. Soc. 1984, 106, 4049.

34. Yang, W.; Mortier, W. J.; J. Am. Chem. Soc. 1986, 108, 5708.

35. Contreras, R. R.; Fuentealba, P.; Galvan, M.; Perez, P.; Chem. Phys. Lett. 1999, 304, 405.

36. Morell, C.; Grand, A.; Toro-Labbe, A.; J. Phys. Chem. A 2005, 109, 205.

37. Becke, A. D.; J. Chem. Phys. 1993, 98, 5648.

38. Becke, A.D.; Phys. Rev. A 1988, 38, 3098.

39. Zhao, Y.; Truhlar, D. G.; Theor. Chem. Acc. 2008, 120, 215.

40. Wanga, Y.; Jina, X.; Yub, H. S.; Truhlar, D. G.; Hea, X.; PNAS 2017, $114,8487$.

41. Chai, J.-D.; Head-Gordon, M.; Phys. Chem. Chem. Phys. 2008, 10, 6615 .
42. Krishnan, R.; Binkley, J. S.; Seeger, R.; Pople, J. A.; J. Chem. Phys. 1980, 72,650 .

43. McLean, A. D.; Chandler, G. S.; J. Chem. Phys. 1980, 72, 5639.

44. Miertus, S.; Tomasi, J.; J. Chem. Phys. 1982, 65, 239.

45. Miertus, S., Scrocco, E.; Tomasi, J.; J. Chem. Phys. 1981, 55, 117

46. Frisch, M. J.; Trucks, G. W.; Schlegel, H. B.; Scuseria, G. E.; Robb, M. A.; Cheeseman, J. R.; Scalmani, G.; Barone, V.; Petersson, G. A.; Nakatsuji, H.; Li, X.; Caricato, M.; Marenich, A. V.; Bloino, J.; Janesko, B. G.; Gomperts, R.; Mennucci, B.; Hratchian, H. P.; Ortiz, J. V.; Izmaylov, A. F.; Sonnenberg, J. L.; Williams-Young, D.; Ding, F.; Lipparini, F.; Egidi, F.; Goings, J.; Peng, B.; Petrone, A.; Henderson, T.; Ranasinghe, D.; Zakrzewski, V. G.; Gao, J.; Rega, N.; Zheng, G.; Liang, W.; Hada, M.; Ehara, M.; Toyota, K.; Fukuda, R.; Hasegawa, J.; Ishida, M.; Nakajima, T.; Honda, Y.; Kitao, O.; Nakai, H.; Vreven, T.; Throssell, K.; Montgomery, J. A., Jr.; Peralta, J. E.; Ogliaro, F.; Bearpark, M. J.; Heyd, J. J.; Brothers, E. N.; Kudin, K. N.; Staroverov, V. N.; Keith, T. A.; Kobayashi, R.; Normand, J.; Raghavachari, K.; Rendell, A. P.; Burant, J. C.; Iyengar, S. S.; Tomasi, J.; Cossi, M.; Millam, J. M.; Klene, M.; Adamo, C.; Cammi, R.; Ochterski, J. W.; Martin, R. L.; Morokuma, K.; Farkas, O.; Foresman, J. B.; Fox, D. J.; Gaussian 09, Revision A.01, Gaussian, Inc., Wallingford CT, 2009.

47. Gaussview Rev. 3.09, Windows version, Gaussian Inc., Pittsburgh.

48. Poland, A.; Palen, D.; Glover, E.; Nature 1982, 300, 271.

49. Orozco-Valencia, A. U.; Vela, A.; J. Mex. Chem. Soc. 2012, 56, 294.

50. Arulmozhiraja, S.; Fujii, T.; Sato, G.; Mol. Phys. 2002, 100, 423.

51. Arulmozhiraja, S.; Selvin, P.C.; Fujii, T.; J. Phys. Chem., A 2002, 106, 1765.

52. Sarkar, U.; Roy, D. R.; Chattaraj, P. K.; Parthasarathi, R.; Padmanabhan, J.; Subramanian, V.; J. Chem. Sci. 2005, 117, 599.

53. https://www.federalregister.gov/documents/2017/07/05/2017-14107/ indaziflam-pesticide-tolerances, accessed June 2019

54. http://pmep.cce.cornell.edu/profiles/herb-growthreg/fatty-alcoholmonuron/indaziflam/indaziflam_reg_1012.pdf, accessed June 2019.

55. Hirshfeld, L.; Theor. Chem. Acc. 1977, 44, 129.

56. Bulat, F.; Chamorro, E.; Fuentealba, P.; Toro-Labbé, A.; J. Phys. Chem. A 2004, 108, 342

57. Senthilkumar, L., Umadevi, P., Nithya, K. N.; Kolandaivel, P.; J. Mol. Model. 2013, 19, 3411 